列

7

\title{
ANALYSIS OF THE BOILING LIQUID EXPANDING VAPOR EXPLOSION (BLEVE) OF A LIQUEFIED NATURAL GAS ROAD TANKER: THE ZARZALICO ACCIDENT
}

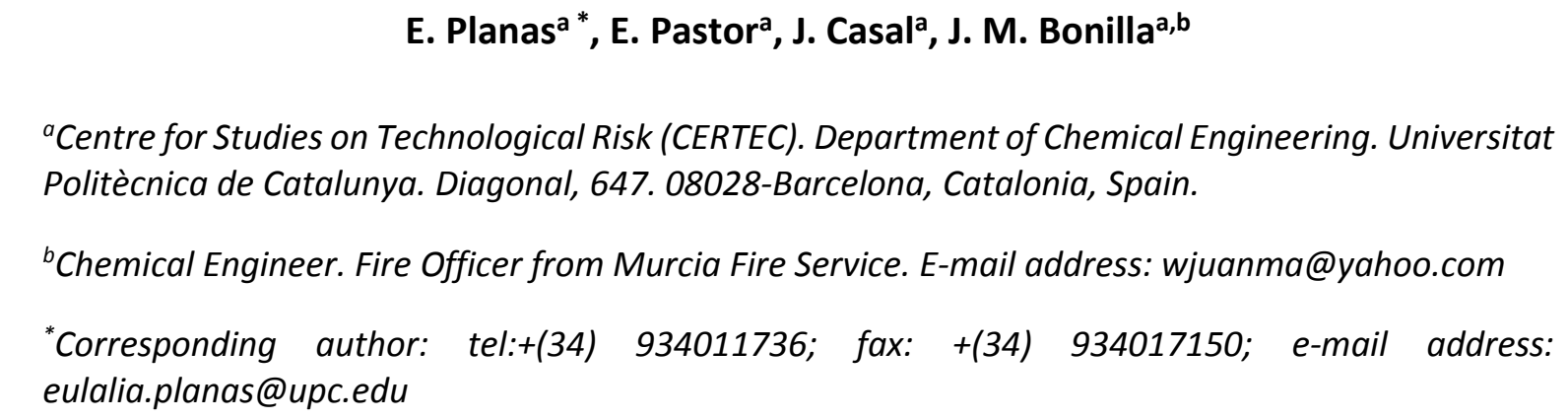

\section{Abstract}

The road accident of a tanker transporting liquefied natural gas (LNG) originated a fire and, finally, the BLEVE of the tank. This accident has been analyzed, both from the point of view of the emergency management and the explosion and fireball effects. The accidental sequence is described: fire, LNG release, further safety valves release, flames impingement on vessel unprotected wall, vessel failure mode, explosion and fireball. According to the effects and consequences observed, the thermal radiation and overpressure are estimated; a mathematical model is applied to calculate the probable mass contained in the vessel at the moment of the explosion. The peak overpressure predicted from two models is compared with the values inferred from the accident observed data. The emergency management is commented.

Keywords: LNG, Fireball, Road transportation, Blast, Thermal radiation.

\section{Highlights}

- Road transportation of LNG is increasing, this implying a certain risk

- The BLEVE of an LNG road tanker -a rather unusual accident- is analyzed

- The effects of explosion and fireball are estimated from the observed consequences

- The correct emergency management avoided further damage to people 


\section{INTRODUCTION}

3

4

The use of natural gas (NG) as an energy source is widely spread in the European Union (EU) and is expected to increase from $44.5 \times 10^{10} \mathrm{~m}^{3}$ in 2010 (Mertens, 2011) to approximately $2,5 \times 10^{11} \mathrm{~m}^{3}$ in 2030 (Kavalov, Petric, \& Georgakaki, 2009). Currently, natural gas comes mostly from Russia (32\%), Norway (28\%), Algeria (15\%) and Qatar (9\%), the main importing countries being Italy (23\%), Germany (22\%), France (15\%), United Kingdom (12\%) and Spain (11\%) (Mertens, 2011). In most of these NG-consuming countries, the gas comes generally transported through a complex net of pipelines; however, in some others, the gas also gets inland through Liquefied Natural Gas (LNG) seaport terminals and then it is distributed by pipelines and by road. LNG terminals have been pointed out as strategic infrastructures for covering Europe's near future needs of NG (Cambridge Econometrics, 2010). At present, there are more than 30 LNG import terminals (Figure 1) distributed along the coastline of different European countries (e.g. Italy, Spain, France, Belgium, UK); some more are expected to be operative in the near future in order to fulfil the increasing demand of NG. With the proliferation of LNG terminals, it is reasonable to expect an intensification of the LNG regional road transport and hence an increase of accident probability.

With the greatest number of LNG import terminals in EU, Spain has an intense traffic of LNG transportation by road, hosting the biggest LNG road distribution companies in Europe. On October $20^{\text {th }} 2011$, a tanker having loaded $19,600 \mathrm{~kg}$ of LNG at the LNG terminal of Cartagena had an accident in Zarzalico (Lorca, Murcia, Spain). As a result of the accident, the tanker caught fire and eventually exploded, causing death to the truck driver. It must be said that this was not the first accident of this type in Spain; on June $22^{\text {th }} 2002$ a similar event involving a LNG road tanker occurred in Tivissa (Tarragona, Spain), killing one person and injuring two more (Planas-Cuchi, Gasulla, Ventosa, \& Casal, 2004). Furthermore, it is worth noting that these two are not the only accidents registered in Spain involving LNG road transport, although they are certainly the only ones in which an explosion of the tanker occurred, and to the best of our knowledge, the only ones occurred worldwide.

It is definitely important to conduct studies on the causes and consequences derived from this type of accidents, as they constitute the only source of experimental data available at full scale that can help improving safety in road transport of LNG. In this paper, the Zarzalico accident is analysed in order to raise awareness about such explosions and try to reduce its future impact. 


\section{ACCIDENTS OCCURRED IN SPAIN DURING THE TRANSPORTATION OF LNG}

3

4

Spain has registered 15 accidents of LNG road tankers during the last 15 years. The influence zones of the ports of Barcelona, Sagunto, Cartagena and Huelva, hosting around the $75 \%$ of the total LNG terminals storage capacity in Spain (Enagas, 2013), have been the most affected one. The most hazardous spot identified has been the area of influence of Huelva port terminal, where $60 \%$ of the accidents have occurred. Figure 2 shows the location, typology and consequences of the reported accidents. 5 different types of final events have been identified and classified from less to more dangerous, being the tanker overturning the most frequent one (7 of 15 accidents). This type of event hardly has major consequences; however, it can sometimes be the initiator of more serious scenarios, like tires and cabin truck fires or losses of containment, leading the latter to LNG releases that can derive into gas fires and explosions if there is an ignition source. Deaths have been accounted in some of the reported accidents where the truck overturning has been followed by an LNG leak. The most severe cases were the previously mentioned accident occurred in Tivissa, with one casualty, several people injured and a house spoiled, and the one of Zarzalico analysed in this paper, where the fire and subsequent explosion caused, besides the death of the driver, several damaged assets including a petrol station.

\section{DESCRIPTION OF THE ACCIDENT}

The accident occurred at kilometre 3.5 of the westbound lane of the A-91 highway (S 593036, E 4164092) that connects Puerto Lumbreras with Granada (Figure 3). At this point, the hard shoulder of the highway is delimited by a $10 \mathrm{~m}$ height bank of soil and rock. There is an inhabited country house $90 \mathrm{~m}$ apart northwards from the accident point, which is next to the service road that runs parallel to the main highway. Next to the opposite lane of the highway, approximately $125 \mathrm{~m}$ apart from the spot where the explosion took place, there is a service area with a petrol station, a coffee bar and a rest area for heavy vehicles.

Around 8 am, a truck driving westwards carrying two large precast concrete panels broke down and stopped on the hard shoulder of the highway, partially invading the lane (see Figure 4). Roughly twenty minutes later, the LNG tanker collided with the rear of the parked vehicle. Due to the 
collision, the driver lost control. The tanker surpassed the parked truck, broke the guardrail and slammed into the ditch against the bank $20 \mathrm{~m}$ ahead of the truck. The tanker got leaning downslope on its wheels slightly tilted to the right, with his tractor head turned (scissor effect) and trapped between the trailer and the bank.

Witnessed by several people who were at the service area, the tanker suddenly ignited just after its full stop. The fire quickly exhibited big flames, which prevented the driver of the broken down vehicle from rescuing his trapped colleague.

The emergency services received a call reporting the accident at 8:21 am, which activated Lorca's fire crews, located $31 \mathrm{~km}$ apart from the accident spot. When the fire fighters got to the place, the tanker had already lost a significant portion of the envelope and the insulation, and it was burning with clearer smoke, which revealed that the fuel involved in the fire was mainly coming from the tank content at that moment.

Fire responders decided to block off a $600 \mathrm{~m}$ radius area and to cut the traffic completely due to the risk of an explosion. The fire trucks were moved $150 \mathrm{~m}$ away, and all people from the service area and several bystanders witnessing the scene from the bridge over the motorway were evacuated. Moments before the explosion, a shrill whistle from the tank was heard, the fire intensified, and so firefighters decided to withdraw to a distance of $200 \mathrm{~m}$. Immediately after this, the explosion of the tank occurred.

\section{DESCRIPTION OF THE ROAD TANK}

There are currently two types of road tankers used in Spain for the transport of liquefied natural gas, in accordance with the European Agreement concerning the International Carriage of Dangerous Goods by Road (United Nations, 2010). These two classes are different concerning basically the type of insulation, whether they are vacuum insulated or polyurethane insulated tanks. The former class comprises double-hull tankers, being the inner tank made of stainless steel and the outer of carbon steel. Thermal insulation is obtained by an insulating material (e.g. perlite) combined with a high degree of vacuum between both hulls. The latters' configuration is single-hull tanker, made of stainless steel, covered by an envelope of polyurethane foam and a lacquered 
1 aluminium shell. The tanker involved in this accident was of the latter type and so was the tank that

2 exploded in 2002 in Tivissa (Planas-Cuchi, Gasulla, et al., 2004).

3 The tanker main characteristics are summarized in Table 2. It has, centred in its bottom, a protective

4 enclosure containing different valves and safety elements as follows:

5 i) There are three filling and discharge outlets (two for liquid phase and one for gas phase) 6 which have a double-valve system pneumatically operated. One of these is a plug seat 7 valve, which guarantees the airtightness of the tank, preventing leaks through any of

ii) Three safety valves, two calibrated at 7 bar (service pressure) and one at 9.1 bar (test pressure). These pressure relief devices have direct communication with the vapour phase of the tank at the mid-length of the top centreline through an immersion tube, which runs along the bottom of tank beneath the insulator and rises following the front of the tank to the top, where it connects with the vessel. The outlet pipe of these valves ascends, permanently under the polyurethane cover, surrounding the tank at its central part and running backwards along the top of the tank towards the rear end, communicating with the vent discharge device.

iii) The enclosure also contains two emergency emptying valves, connected to their respective pipelines, which are fixed at lateral inner generatrices of the tank. The extremes of these lines reach the height of the longitudinal axis of the tank in such a way that, in case of overturning at $90^{\circ}$ or $270^{\circ}$, one end always remains in the liquid phase and the other one in the gas, allowing emergency emptying.

iv) Two maximum filling valves connected to siphon pipes which run upwards inside the tank up to its maximum filling height (United Nations, 2010); one of them corresponds to the $85 \%$ of the total tank capacity and the other to the $95 \%$ for emergency transfers. v) A control level device, which connects the liquid and the gas phase to their respective pressure gauges and calculates the fill level by relating the hydrostatic pressure of the liquid with the pressure inside the tank. images do not allow distinguishing which elements were affected, although it seems reasonable to 
assume that some pipes not equipped with plug systems (therefore ruling out the filling-discharging system) were damaged.

\section{ANALYSIS OF THE SEQUENCE AND CONSEQUENCES OF THE ACCIDENT}

The analysis of the sequence of the accident by means of pictures and accounts of the witnesses and of the consequences observed on diverse points around the accident, together with the use of adequate mathematical models, can lead to a better understanding of what did happen in this accident and what could be expected in similar events. Moreover, this investigation can contribute to a better knowledge of the BLEVE phenomenon. This kind of analysis is not new (Brambilla \& Manca, 2010; Bubbico \& Marchini, 2008; Demichela, Piccinini, \& Poggio, 2004; Manca \& Brambilla, 2010; Planas-Cuchi, Gasulla, et al., 2004) but it is very important to raise awareness of such explosions and to design new prevention strategies.

\subsection{Sequence of the accident}

As described in section 3, the LNG tank car caught fire immediately after the collision. Initially the flames generated black smoke and surrounded the whole tank (Figure 5), which suggests that probably the wheels, the diesel of the tank and/or the polyurethane insulation were burning. It is difficult to say if at that point LNG was also contributing to the fire, although it is possible that one of the pipes or valves (as described in section 4) could have been broken in the collision and therefore be leaking. Looking at the images taken by the eyewitnesses, what does seem clear is that after this first stage (around 8:35 h), the fire aspect changed significantly. It had brighter flames and much less black smoke, which would indicate that it was essentially fueled by natural gas through a leak somewhere in the central part of the tank hidden by the bank (Figure 6). The bright aspect of the flames clearly indicates that liquid or two-phase mixture was being released; when this happens, the combustion is poorer as compared to a pure gas flame (which would be almost transparent), and the existence of soot particles originates much more luminous flames (Palacios, Muñoz, Darbra, \& Casal, 2012).

When firefighters arrived, at 8:40 $\mathrm{h}$ (Figure 7), they noted that almost all the insulation had been destroyed by the accident and the fire, except for the bottom rear of the tank. The fire was at that moment surrounding mainly the central part and the top of the tank. Fire at the top of the tank can 
be explained by the opening of the safety relief valves, discharging LNG as a jet fire impinging on the

2 top of the tank surface. The valves never stopped discharging until the tank exploded at 9:32 $\mathrm{h}$

3 (Figure 8); therefore, it can be assumed that the flow rate through each valve was at its maximum

4 (150 kg $\cdot \mathrm{h}^{-1}$ according to the manufacturer specifications) during approximately one hour. What is unknown is if the three valves were open or only the ones set at 7-bar pressure.

At 9:31 $\mathrm{h}$ firefighters located at $150 \mathrm{~m}$ from the tank heard whistles and crackling sounds. They also saw changes in the brightness of the flames, which made them decide withdrawing further away. When they were already located approximately $200 \mathrm{~m}$ far from the tank, between $30-40 \mathrm{~s}$ after they heard the whistles, the tank exploded. There are three plausible hypotheses that could explain this last sequence of events:

1. Since the truck was equipped with three safety valves (two set at 7 bar and one set at 9.1 bar), it is possible that, until then, the only opened valves were the ones at 7 bar. Due to the long exposure of the tank to fire and to its progressive heating, these two valves were unable to keep the pressure in the container and the third valve opened, originating the whistles heard by the witnesses. Some seconds later, the total loss of containment took place according to a one-step BLEVE mode of failure (Birk, Davison, \& Cunningham, 2007).

2. All three valves were already opened and therefore the tank pressure was at least 9.1 bar when an initial rupture crack was formed. This event was responsible for the whistles heard by the witnesses and for the increase in the flames aspect due to the vapor escaping from the opening. The initial crack could have stopped because of the sudden reduction of the tank pressure and the cooling effect of the released two-phase stream. However, after approximately $30 \mathrm{~s}$, the flashing of the liquid due to this sudden loss of pressure, together with the heat impinging and weakening the tank would have restarted de crack and caused de total loss of containment, according to a two-step BLEVE mode of failure (Birk et al., 2007).

3. An intermediate situation in which the pressure was maintained between 7 and 9.1 bar, due to the release of LNG from two safety valves and from a broken pipe, remaining the 9.1 bar safety valve closed. At a given moment, being the tank unable to keep the internal pressure due to the loss of mechanical strength because of the high wall temperature, a crack was formed, progressing later and leading to the vessel explosion. 
1 It is worth noting that in the hypotheses one and two, the pressure just before the explosion would

2 have been 9.1 bar, while in the third one it would have been 7 bar. After the explosion, a fireball lasting some seconds (about $10 \mathrm{~s}$ according to the witnesses) was observed.

4 The content of the tank just before the explosion is unknown due to the losses occurred through the safety valves and the leakage on the central part of the tank, located most likely in one of the pipes connected to the devices inside the protective enclosure. The remains of the tank just after the explosion can be seen in Figure 9.

\subsection{Consequences of the accident}

Three types of effects where observed in this accident: overpressure due to the explosion, projection of vessel fragments and radiation due to the fireball. The consequences associated with these effects were observed mainly in the surroundings and the objects located within a radius of

$12200 \mathrm{~m}$. There were no casualties (apart from the driver of the truck due to the initial shock), nor injured.

Concerning the fireball consequences, it was observed that over a radius of approximately $50 \mathrm{~m}$ vegetation and traffic signals were severely burned, and at $90 \mathrm{~m}$ pine needles had underwent pyrolysis. There was no information from the witnesses concerning the dimensions and height of the fireball. However, some interesting information could be obtained from a tree located $90 \mathrm{~m}$ from the tank (see Figure 10), because its leaves (those facing the fireball) were completely dried and pyrolysed due to the radiation received (direct impingement of flames can be completely discarded). According to data reported in the literature (Landucci et al., 2011; Quintiere, 2006) and

21 discussions with experts on ignition phenomena (Simeoni \& Thomas, 2013), a heat flux around 55 $22 \mathrm{~kW} \cdot \mathrm{m}^{-2}$ would be required during the fireball duration (approximately $10 \mathrm{~s}$ ) to completely dry and 23 pyrolyse the pine needles. This value has been used to estimate the fireball dimensions and, with 24 this information, the contents of the vessel just before the explosion. A shorter time, for example 5 $25 \mathrm{~s}$, would have required a thermal radiation intensity of approximately $90 \mathrm{~kW} \cdot \mathrm{m}^{-2}$, which would 26 correspond to a fuel mass in the fireball larger than the initial contents of the vessel (see section $27 \quad 6.1)$

Concerning the consequences due to the overpressure generated by the tank explosion, they were mostly observed at the gas station, located at $125 \mathrm{~m}$ from the tank (see Figure 11). Large windowpanes of considerable thickness fell down because the mounting of the frame failed. Smaller 
1 windows remained essentially unaffected. This suggests that a side-on overpressure value between

20.02 and 0.03 bar (Casal, 2008; Lees \& Mannan, 2005) was achieved at this location. It is important

3 to emphasize here that next to one side of the tank there was a $10 \mathrm{~m}$ high hill slope, which would

4 have reflected the overpressure wave towards the gas station.

5 Finally, concerning the projection of missiles, the vessel was broken into three large fragments and 6 other minor pieces such as the baffles that were mostly found in a radius of $200 \mathrm{~m}$. The distribution

7 was not the typical one expected from this type of vessels, due to the presence of the slope. The

8 tank three major pieces remained near the explosion point, while other minor pieces (such as the

9 baffles) were spread around, most of them at the side were the gas station was located.

\section{QUANTITATIVE ANALYSIS}

12 This type of analysis usually starts from the initial event, estimating the mass of substance lost 13 before the explosion. Then, taking into account the pressure inside the tank, the overpressure 14 generated can be calculated according to one of the models available in the literature. Finally, the 15 fireball is estimated following the solid flame model. Nevertheless, as explained in section 5, in the 16 present accident the mass lost and the pressure inside the vessel just before the explosion are 17 unknown. Therefore, in this case, the effects observed from the fireball have been used to estimate 18 the contents of the vessel just before the explosion, and then with this datum the overpressure has 19 been estimated.

\subsection{The fireball and the contents of the vessel before the explosion}

21 To predict the effects from a fireball (i.e. the radiation received by a given target located at a 22 particular distance), the solid flame model can be applied (Casal, 2008). In this case, taking into 23 account the location of the tree (see Figure 12), the equations listed below (being the atmospheric 24 conditions $T_{a}=16^{\circ} \mathrm{C}, R H=50 \%$ ), an estimated value of $I=55 \mathrm{~kW} \cdot \mathrm{m}^{-2}$ and an initial value of $t=$ $2510 \mathrm{~s}$, it is possible to calculate, by an iterative process, the approximate mass of fuel involved in the 26 fireball of $M=12,000 \mathrm{~kg}$.

27 Summary of equations used to apply the solid flame model to the fireball:

$$
I=\tau \cdot F \cdot E_{p}
$$




$$
\begin{gathered}
\tau=2.02 \cdot\left(P_{w} \cdot d\right)^{-0.09} \\
P_{w}=P_{w a} \cdot \frac{R H}{100} \\
\ln \left(P_{w a}\right)=23.18986-\frac{3816.42}{\left(T_{a}-46.13\right)} \\
F=\frac{D^{2}}{4 \cdot(D / 2+d)^{2}} \\
E_{p}=\frac{\eta_{r a d} \cdot M \cdot \Delta H_{c}}{\pi \cdot D^{2} \cdot t} \\
\eta_{r a d}=0.00325 \cdot P^{0.32} \\
D=5.8 \cdot M^{1 / 3} \\
t=0.9 \cdot M^{0.25} \\
H=0.75 \cdot D \\
d=\left(x^{2}+(H-16)^{2}\right)^{1 / 2}-\frac{D}{2}
\end{gathered}
$$

1

2 Once the mass of fuel known, the geometric characteristics of the fireball and its duration can also 3 be estimated:

4

5

6

7 These results are consistent with the observed effects of thermal radiation over the ground, as 8 described in section 5.2. Moreover, from the mass remaining in the tank just before the explosion, 9 in can be concluded that around $8,000 \mathrm{~kg}$ of natural gas were lost before the explosion ( $40 \%$ of the 10 total contents). Taking into account the maximum flow that the safety valves could discharge (150 $11 \mathrm{~kg} \cdot \mathrm{h}^{-1}$ ) and that they would have been discharging during 1 hour approximately, it is sure that there 12 was a leak from somewhere else. Still, it remains unclear whether only the two valves set at 7 bar 13 were open or the valve set at 9.1 bar was open as well.

14 


\subsection{The BLEVE and the pressure inside the vessel before the explosion}

2 The mass of fuel calculated in the previous section has been used to estimate the overpressure

3 generated by the BLEVE explosion following the method proposed by Planas-Cuchi et al. (Planas-

4 Cuchi, Salla, \& Casal, 2004) which, according to several authors (Bubbico \& Marchini, 2008;

5 Laboureur, Heymes, Lapebie, Buchlin, \& Rambaud, 2014) seems to be the most realistic approach.

6 This method takes into account the real expansion work done when the whole content of the vessel

7 changes from the explosion state to the final state, considering real gas behavior and adiabatic

8 irreversible expansion. This work must be equal to the change in internal energy of the vessel

9 content:

$$
E=-P \cdot \Delta V=\Delta U
$$

$$
-\Delta U=\left(u_{L 0}-u_{V 0}\right) \cdot m_{T} \cdot x-m_{T} \cdot u_{L 0}+U
$$

$$
x=\frac{m_{T} \cdot P \cdot v_{L 0}-V_{T} \cdot P+m_{T} \cdot u_{L 0}-U}{\left[\left(u_{L 0}-u_{V 0}\right)-\left(v_{V 0}-v_{L 0}\right) \cdot P\right] \cdot m_{T}}
$$

13 The vessel pressure just before the explosion must be known to apply this method and, as said in 14 the previous sections, we can only hypothesize that the pressure was probably at some point between 7 to 9.1 bar. Therefore, calculations have been performed for these two values to obtain the explosion energy, $E$ (see Table 3).

17 Once the explosion energy is known, diverse methods can be used to estimate the overpressure reaching a given target (Baker, Cox, Kulesz, Strehlow, \& Westine, 1983; CCPS, 2010; Planas \& Casal, 19 2015).

20 The most widely used method is the one in which the explosion energy is converted into TNT

21 equivalent mass (see equation (15)), taking into account the energy of the TNT, $\Delta H_{T N T}$ 22 (approximately $4.68 \mathrm{MJ} \cdot \mathrm{kg}^{-1}$ ); most authors assume that the fraction of the total energy converted 23 into pressure wave, $\beta$, is 0.5 :

$$
W_{T N T}=\frac{\beta \cdot E}{\Delta H_{T N T}}=1.068 \cdot 10^{-7} \cdot E
$$


2 Once the TNT equivalent mass is known, the scaled distance can be obtained:

$$
d_{n}=\frac{R}{\left(W_{T N T}\right)^{1 / 3}}
$$

3

4 and the overpressure is then estimated by using a $\Delta P$ vs. $d_{n}$ diagram for a surface explosion (Casal,

5 2008). This method takes into account the ground reflection of the pressure wave when the 6 explosion takes place on the ground.

7 The calculation has also been performed by the method proposed by the TNO (van den Bosch et al., 8 2005). This method assumes real gas behavior and isentropic expansion to estimate the explosion 9 energy. Then also uses the graph of a non-dimensional pressure vs. non-dimensional distance (in 10 this case, based on pentolite) (Baker et al., 1983) to estimate the overpressure; this graph doesn't 11 take into account the ground reflection and therefore this is considered in equation (24). These are 12 the equations used:

13

$$
\begin{gathered}
X_{L}=\frac{s_{L 1}-s_{L 0}}{s_{V 0}-s_{L 0}} \\
X_{V}=\frac{s_{V 1}-s_{L 0}}{s_{V 0}-s_{L 0}} \\
u_{L 0}=\left(1-X_{L}\right) \cdot h_{L 0}+X_{L} \cdot h_{V 0}-\left(1-X_{L}\right) \cdot P_{0} \cdot v_{L 0}-X_{L} \cdot P_{0} \cdot v_{V 0} \\
u_{V 0}=\left(1-X_{V}\right) \cdot h_{L 0}+X_{V} \cdot h_{V 0}-\left(1-X_{V}\right) \cdot P_{0} \cdot v_{L 0}-X_{V} \cdot P_{0} \cdot v_{V 0} \\
E_{L}=\left(u_{L 1}-u_{L 0}\right) \cdot m_{L} \\
E_{V}=\left(u_{V 1}-u_{V 0}\right) \cdot m_{V} \\
E=E_{L}+E_{V} \\
E_{p w a v e}=2 \cdot E \\
\bar{R}=R \cdot\left(\frac{P_{0}}{E_{\text {pwave }}}\right)^{1 / 3} \\
\Delta P=\bar{P}_{S} \cdot 1.01325
\end{gathered}
$$


1 This method assumes - with a conservative approach- that all the released energy is converted in

2 pressure wave (i.e., $\beta=1$ ). The overpressure value obtained with equation (26) must be later

3 adjusted to take into account the geometry effects. For cylindrical vessels $\Delta P$ has to be multiplied

$4 \quad$ by 4 if $\bar{R}<0.3$, by 1.6 if $0.3<\bar{R}<3.5$ and by 1.4 if $\bar{R}>3.5$.

5 The same two values of the pressure inside the vessel just before the explosion ( 7 and 9.1 bar) have 6 been assumed, as in the previous method. Results have been summarized in Table 4. Important

7 differences are obtained between both methods, being the results from the isentropic (adiabatic

8 reversible) assumption more than 300\% larger than those corresponding to the adiabatic

9 irreversible assumption.

10 Another aspect should be taken into account in this specific case: the presence of a practically 11 vertical wall next to one side of the vessel adds a new reflection to the pressure wave (see Figure 12 13), not taken into account so far. Therefore, in the case of the Planas-Cuchi et al. method, the same 13 equations have been applied but using the energy value $E$ multiplied by 2:

$$
W_{T N T}=\frac{\beta \cdot 2 \cdot E}{\Delta H_{T N T}}=2.136 \cdot 10^{-7} \cdot E
$$

And in the case of the TNO method, expression (24) has been substituted by:

$$
E_{\text {pwave }}=4 \cdot E
$$

17 In order to compare the results of the peak overpressure generated by the blast wave according to 18 both methods, three options have been considered. First the Planas-Cuchi et al. method with the 19 TNT equivalent as described by equations (16) and (27); secondly the original TNO method as 20 described by equations (25), (26) and (28); and finally, this method but including the same factor $\beta$, 21 as used in the first one. All these results have been summarized in Table 5.

22 Looking at the results obtained, it seems that the model proposed by the TNO, even when applying 23 the $\beta=0.5$ factor, tends to overpredict the overpressure, as in all the tested cases gives values 24 around 0.05 bar. The method by Planas-Cuchi et al. provides values in the expected range. However, 25 no large differences are observed between the values obtained at 7 and 9 bar, which does not allow 
extracting definite conclusions concerning the pressure achieved in the tank just before the

2 explosion.

\section{LESSONS LEARNT}

One of the most important results that one should expect from the analysis of past accidents is the extraction of lessons learnt. In this case, from the analysis of the Zarzalico accident, a few lessons can be inferred.

- Even though the tank was insulated with polyurethane, this accident has demonstrated again that both the road accident impact and the fire can destroy significantly the insulating layer. If, as happened in this case, there is a fire, it can affect the vessel. This study case serves to underline the wise move of total banning for non-vacuum insulated tanks manufacturing, by the Spanish Ministry of Industry, Energy and Tourism since September 2013.

- An essential aspect in this type of accident is the possibility that flames impinge on the tank wall. If this happens and impingement takes place above the liquid level, the wall temperature will dramatically increase and, even if safety valves are correctly operating, it is possible that the vessel cannot stand the pressure. In this situation, the explosion can occur at any moment from the beginning of the fire.

- The thermal radiation from the fireball reached a significant distance, covering a circular zone (lethality (1\%) reach: 170 m; first degree burns (1\%) reach: 295 m; both values without any clothing protection). Therefore, the thermal effects must be considered a very important aspect in these accidents.

- The blast effects were as well significant, originating damage to buildings at $125 \mathrm{~m}$. As for the vessel breaking pattern, it was broken in three large fragments (two large fragments are more common: $60 \%$ of cases) which, probably due to the nearby bank wall, remained near the explosion site; however, minor pieces were ejected over distances up to $200 \mathrm{~m}$; this is also an interesting information concerning the safety distances to be considered.

- Although the explosion and fireball effects were severe and covered a large area, neither casualties (except for the car driver, due to the initial crash) nor injured people occurred. This was because the management of the emergency was quite sound, evacuating a $600 \mathrm{~m}$ radius area from the arrival of firefighters and cutting completely the motorway traffic, and later on moving the firefighters themselves from $150 \mathrm{~m}$ to $200 \mathrm{~m}$ away. 


\section{CONCLUSIONS}

3 The continuous increase in the consumption of natural gas is associated to the corresponding

4 growth in the distribution by both cryogenic road tankers and pipelines. Road tankers are exposed

5 to the risk of undergoing a road accident and, in fact, this happens from time to time. In this case,

6 the possibility of having a fire and eventually a BLEVE is not negligible at all.

7 The mathematical models applied have shown a relatively good performance according to the

8 observed thermal and mechanical consequences.

9 The study of such accidents is clearly a useful tool to learn and improve the safety of such 10 transportation mode. It is quite interesting to get a better understanding of them, especially 11 because of the lack of experimental data at large scale. Finally, it is also interesting to highlight that 12 this type of case study may provide support for future understanding and modelling of the behavior 13 of pressure vessels storing cryogenic substances when exposed to fires.

\section{ACKNOWLEDGEMENTS}

17 The authors thank the Spanish Ministry of Economy and Competitiveness (project no. CTQ20011-

18 27285) and the Autonomous Government of Catalonia (projects No. 2009SGR1118 and 19 2014SGR413) for financial support. They are also grateful to Jesus Belmonte and José Marín, fire 20 sergeants from the region of Murcia, for providing valuable graphic information of the accident.

\section{NOMENCLATURE}

$23 d$ Distance between the target and the flame surface, $\mathrm{m}$

$24 \quad d_{n} \quad$ Scaled distance, $\mathrm{m} \cdot \mathrm{kg}^{-1 / 3}$

$25 \quad D \quad$ Diameter of the fireball, $\mathrm{m}$

$26 E \quad$ Explosion energy, J 
$1 \quad E_{L} \quad$ Explosion energy of the liquid, MJ

$2 E_{p} \quad$ Average emissive power of the flames, $\mathrm{kW} \cdot \mathrm{m}^{-2}$

$3 E_{V} \quad$ Explosion energy of the vapor, MJ

$4 \quad E_{\text {pwave }}$ Explosion energy converted into pressure wave, MJ

$5 \quad F \quad$ View factor, --

$6 \quad h_{L 0} \quad$ Enthalpy of the liquid at the final state, $\mathrm{kJ} \cdot \mathrm{kg}^{-1}$

$7 \quad h_{v 0} \quad$ Enthalpy of the vapor at the final state, $\mathrm{kJ} \cdot \mathrm{kg}^{-1}$

$8 H$ Height at which the center of the fireball is located, $\mathrm{m}$

$9 \Delta H_{c} \quad$ Heat of combustion (lower value) of the fuel, $\mathrm{kJ} \cdot \mathrm{kg}^{-1}$

10 I Thermal radiation intensity reaching a given target, $\mathrm{kW} \cdot \mathrm{m}^{-2}$

$11 m_{T} \quad$ Total mass of the vessel content, $\mathrm{kg}$

$12 m_{L} \quad$ Mass of liquid in the vessel at conditions just before the explosion, $\mathrm{kg}$

$13 m_{V} \quad$ Mass of vapor in the vessel at conditions just before the explosion, $\mathrm{kg}$

$14 \quad M \quad$ Mass of fuel in the fireball, $\mathrm{kg}$

$15 P \quad$ Pressure in the vessel just before the explosion, $\mathrm{Pa}$

$16 \quad P_{0} \quad$ Atmospheric pressure, $\mathrm{Pa}$

$17 \quad \bar{P}_{S} \quad$ Dimensionless pressure, --

$18 P_{w} \quad$ Partial pressure of water in the atmosphere, $\mathrm{Pa}$

$19 P_{w a} \quad$ Saturated water vapor pressure at the atmospheric temperature, $\mathrm{Pa}$

$20 \Delta P \quad$ Overpressure generated by the vessel explosion, bar

$21 \quad R \quad$ Distance between the center of the explosion and the point where overpressure must be 22 calculated, $\mathrm{m}$ 
$1 \quad \bar{R} \quad$ Dimensionless distance, --

$2 \quad R H \quad$ Relative humidity, \%

$3 S_{L 0} \quad$ Specific entropy of the liquid at the final state, $\mathrm{J} \cdot \mathrm{kg}^{-1} \cdot \mathrm{K}^{-1}$

$4 S_{V 0} \quad$ Specific entropy of the vapour at the final state, $\mathrm{J} \cdot \mathrm{kg}^{-1} \cdot \mathrm{K}^{-1}$

$5 \quad S_{L 1} \quad$ Specific entropy of the liquid just before the explosion, $\mathrm{J} \cdot \mathrm{kg}^{-1} \cdot \mathrm{K}^{-1}$

$6 \quad s_{V 1} \quad$ Specific entropy of the vapour just before the explosion, $\mathrm{J} \cdot \mathrm{kg}^{-1} \cdot \mathrm{K}^{-1}$

$7 \quad t \quad$ Time corresponding to the duration of the fireball, $\mathrm{s}$

$8 \quad T_{a} \quad$ Ambient temperature, $\mathrm{K}$

$9 \quad u_{L 0} \quad$ Specific internal energy of the liquid at the final state of the adiabatic process, $\mathrm{J} \cdot \mathrm{kg}^{-1}$

$10 u_{V 0} \quad$ Specific internal energy of the vapour at the final state of the adiabatic process, $\mathrm{J}^{\mathrm{kg}} \mathrm{g}^{-1}$

$11 u_{L 1} \quad$ Specific internal energy of the liquid just before the explosion, $\mathrm{J} \cdot \mathrm{kg}^{-1}$

$12 u_{V 1}$ Specific internal energy of the vapour just before the explosion, $\mathrm{J} \cdot \mathrm{kg}^{-1}$

$13 U$ Overall internal energy of the vessel at conditions just before the explosion, J

$14 \Delta U$ Overall variation of the internal energy of the vessel content, J

$15 v_{V 0} \quad$ Specific volume of vapor at the final state of the adiabatic process, $\mathrm{m}^{3} \cdot \mathrm{kg}^{-1}$

$16 v_{L 0} \quad$ Specific volume of liquid at the final state of the adiabatic process, $\mathrm{m}^{3} \cdot \mathrm{kg}^{-1}$

$17 \quad V_{T} \quad$ Total vessel volume, $\mathrm{m}^{3}$

$18 \Delta V \quad$ Volume variation of the total content of the vessel when changing from the explosion state 19 to atmospheric pressure conditions, $\mathrm{m}^{3}$

$20 W_{T N T}$ Equivalent mass of TNT, $\mathrm{kg}$

$21 \Delta H_{T N T}$ TNT energy of explosion, $\mathrm{J} \cdot \mathrm{kg}^{-1}$ 
$1 x \quad$ Vapour fraction (with respect to the total mass) at the final state of the adiabatic irreversible

2 process, --

$3 \quad X_{L} \quad$ Vapor ratio of saturated liquid, --

$4 \quad X_{V} \quad$ Vapor ratio of saturated vapor, --

$5 \quad \beta \quad$ Fraction of the explosion energy converted into blast wave, --

$6 \quad \tau \quad$ Atmospheric transmissivity, --

$7 \quad \eta_{\text {rad }} \quad$ Radiant heat fraction, --

REFERENCES

10

11

12

Baker, W. E., Cox, P. A., Kulesz, J. J., Strehlow, R. A., \& Westine, P. S. (1983). Explosion Hazards and Evaluation. Elsevier.

Birk, A. M., Davison, C., \& Cunningham, M. (2007). Blast overpressures from medium scale BLEVE tests. Journal of Loss Prevention in the Process Industries, 20(3), 194-206.

Blikom, L. P. (2011). Website LNG Energy of the future. Retrieved June 06, 2014, from http://blogs.dnv.com/Ing/2011/03/4-ways-to-distribute-tea-cups-of-Ing/

Bonilla Martinez, J. M., Belmonte Pérez, J., \& Marín Ayala, J. A. (2012). Analysis of the explosion of a liquefied-natural-gas road tanker. Seguridad Y Medio Ambiente. Fundación Mapfre, 1-20.

Brambilla, S., \& Manca, D. (2010). The Viareggio LPG railway accident: event reconstruction and modeling. Journal of Hazardous Materials, 182(1-3), 346-57. doi:10.1016/j.jhazmat.2010.06.039

Bubbico, R., \& Marchini, M. (2008). Assessment of an explosive LPG release accident: a case study. Journal of Hazardous Materials, 155(3), 558-65.

Cambridge Econometrics. (2010). The revision of the trans-European energy network policy (TEN-E) (p. 108). Retrieved from http://ec.europa.eu/energy/infrastructure/studies/doc/2010_11_ten_e_revision.pdf

Casal, J. (2008). Evaluation of the Effects and Consequences of Major Accidents in Industrial Plants (1st ed., p. 363). Elsevier.

CCPS, C. for C. P. S. (2010). Guidelines for Vapor Cloud Explosion, Pressure Vessel Burst, BLEVE and Flash Fire Hazards (2nd ed., p. 456). Wiley-AIChE; 2 edition. 
Demichela, M., Piccinini, N., \& Poggio, A. (2004). Analysis of an LPG Accidental Release. Process Safety and Environmental Protection, 82(2), 128-131. doi:10.1205/095758204322972762

Enagas. (2013). Enagas Website. Retrieved June 06, 2014, from http://www.enagas.es/cs/Satellite?pagename=ENAGAS/Page/ENAG_home

Green, D. ., \& Perry, R. H. (2007). Perry's Chemical Engineers' Handbook, Eighth Edition [Hardcover] (p. 2400). McGraw-Hill Professional; 8 edition. Retrieved from http://www.amazon.com/Perrys-Chemical-Engineers-Handbook-Edition/dp/0071422943

Kavalov, B., Petric, H., \& Georgakaki, A. (2009). Liquefied Natural Gas for Europe. Joint Research Centre of the European Comission.

Laboureur, D., Heymes, F., Lapebie, E., Buchlin, J. M., \& Rambaud, P. (2014). BLEVE Overpressure : Multiscale Comparison of Blast Wave Modeling, 33(3). doi:10.1002/prs

Landucci, G., Tugnoli, A., Busini, V., Derudi, M., Rota, R., \& Cozzani, V. (2011). The Viareggio LPG accident: Lessons learnt. Journal of Loss Prevention in the Process Industries, 24(4), 466-476. doi:10.1016/j.jlp.2011.04.001

Lees, F. P., \& Mannan, M. S. (2005). Lees' Loss Prevention in the Process Industries: Hazard Identification, Assessment and Control. (M. S. Mannan, Ed.) (3rd ed.). Elsevier-Butterworth Heinemann.

Manca, D., \& Brambilla, S. (2010). Complexity and uncertainty in the assessment of the Viareggio LPG railway accident. Journal of Loss Prevention in the Process Industries, 23(5), 668-679. doi:10.1016/j.jlp.2010.07.007

Mertens, R. (2011). Energy, transport and environment indicators 2012. Eurostat Pocketbook. (Eurostat, Ed.). Publications Office of the European Union. Retrieved from http://epp.eurostat.ec.europa.eu/cache/ITY_OFFPUB/KS-DK-12-001/EN/KS-DK-12-001EN.PDF

Palacios, A., Muñoz, M., Darbra, R. M., \& Casal, J. (2012). Thermal radiation from vertical jet fires. Fire Safety Journal, 51, 93-101. doi:10.1016/j.firesaf.2012.03.006

Planas, E., \& Casal, J. (2015). BLEVE-Fireball. In Handbook of Combustion (Vol. (in press), p. 23). Wiley.

Planas-Cuchi, E., Gasulla, N., Ventosa, A., \& Casal, J. (2004). Explosion of a road tanker containing liquified natural gas. Journal of Loss Prevention in the Process Industries. doi:10.1016/j.jlp.2004.05.005

Planas-Cuchi, E., Salla, J. M., \& Casal, J. (2004). Calculating overpressure from BLEVE explosions. Journal of Loss Prevention in the Process Industries, 17(6), 431-436.

Quintiere, J. G. (2006). Fundamentals of fire phenomena. John Wiley \& Sons, Ltd. 
Simeoni, A., \& Thomas, J. (2013). Personal Communication.

United Nations, (UN). (2010). ADR: European Agreement concerning the International Carriage of Dangerous Goods by Road. Retrieved from http://www.unece.org/trans/danger/publi/adr/adr2011/11contentse.html

Van den Bosch, C. J. H., Weterings, R. A. P. M., Duijm, N. J., Mercx, W. P. M., van den Berg, A. C., Engelhard, W. F. J. M., ... van Wees, R. M. M. (2005). CPR 14E: Methods for the calculation of physical effects (Yellow Book). (C. J. H. van den Bosch \& R. A. P. M. Weterings, Eds.) (3rd ed., p. 870). The Hague,: TNO.

Younglove, B. A., \& Ely, J. F. (1987). Thermophysical properties of fluids. II. Methane, Ethane, Propane and Normal Butane. Journal of Physical and Chemical Reference Data, 16(4), 577798. 


\section{TABLES CAPTIONS}

2 Table 1. Accidents occurred in Spain with LNG road tankers since 1999 (modified from Bonilla et al. (Bonilla

3 Martinez, Belmonte Pérez, \& Marín Ayala, 2012)).

4 Table 2. Characteristics of the road tanker involved in the Zarzalico accident.

5 Table 3. Explosion energy obtained according to the model proposed by Planas-Cuchi et al. (2004)*

6 Table 4. Explosion energy obtained according to the model proposed by TNO (van den Bosch et al., 2005)*.

7 Table 5. Peak overpressure (bar) results obtained according to the three methodologies applied.

\section{FIGURES CAPTIONS}

11 Figure 1. LNG terminals in Europe (Blikom, 2011).

12 Figure 2. Accidents occurred in Spain with LNG road tankers since 1999 (modified from (Bonilla Martinez et 13 al., 2012))

14 Figure 3. Location of the place where the accident occurred.

15 Figure 4. Truck carrying two large precast concrete panels stopped on the highway shoulder just after 16 colliding with the LNG tanker at 8:21 h (source: Murcia Fire Service).

17 Figure 5. Truck in flames few minutes after the collision at: (a) 8:25 h, (b) 8:30 h (source: Murcia Fire 18 Service).

19 Figure 6. Fire with brighter flames and less black smoke at 8:35 h (source: Murcia Fire Service)

20 Figure 7. State of the fire when firefighters arrived on site at 8:40 h; now an intense fire is observed on the 21 top of the tank, probably due to the safety venting (source: Murcia Fire Service).

22 Figure 8. One of the latest images before the explosion, taken at 9:30 h (source: Murcia Fire Service).

23 Figure 9. Vessel condition after failure. a) Big fragment that remained near the wall were the truck was

24 stopped; b) Rear view of the previous fragment allowing to see part of the engine and tractor wheels; c)

25 Biggest part of the vessel that remained on the motorway median; d) Previous fragment from another view 26 point.

27 Figure 10. Tree affected by the fireball radiation, located at $90 \mathrm{~m}$ from the tank (source: Murcia Fire Service).

28 Figure 11. Minor damages caused by the explosion to windows and ceilings (source: Murcia Fire Service).

29 Figure 12. Scheme of the fireball position in relation to the tree affected by the radiation

30 Figure 13. Reflection of the pressure wave on the ground and on the presence of a talus.

31 
Table 1.

\begin{tabular}{|l|l|l|c|}
\hline \multicolumn{1}{|c|}{ Date } & \multicolumn{1}{|c|}{ Place } & \multicolumn{1}{|c|}{ Effects } & Consequences \\
\hline $27 / 01 / 1999$ & Sevilla & Tanker tire fire & --- \\
\hline $10 / 10 / 2000$ & Jabugo (Huelva) & Tanker overturning & --- \\
\hline $12 / 06 / 2002$ & Beas (Huelva) & Tanker overturning & $\begin{array}{c}\text { Driver died, some injured, a } \\
\text { home seriously damaged }\end{array}$ \\
\hline $22 / 06 / 2002$ & Tivissa (Tarragona) & Tanker fire and explosion & Driver slightly injured \\
\hline $04 / 12 / 2002$ & Huelva & Tanker overturning & Driver died \\
\hline $24 / 03 / 2004$ & Jabugo (Huelva) & Fire in the truck cabin & Driver died \\
\hline $11 / 10 / 2007$ & Algodonales (Cadiz) & Tanker overturning and leak & --- \\
\hline $19 / 08 / 2008$ & Reolid (Albacete) & Tanker overturning and leak & and a gas station \\
\hline $25 / 10 / 2010$ & Sanlúcar la Mayor (Huelva) & Leak through the valves & --- \\
\hline $20 / 10 / 2011$ & Zarzalico (Murcia) & Tanker fire and explosion & $\begin{array}{c}\text { Driver died, damages to a home } \\
\text { and }\end{array}$ \\
\hline $27 / 10 / 2011$ & Ribarroja (Valencia) & Tanker overturning & Driver seriously injured \\
\hline $21 / 11 / 2011$ & Palos (Huelva) & Rear end crash of empty tank & --- \\
\hline $14 / 01 / 2012$ & Puerto Lumbreras (Murcia) & Empty tanker overturning & --- \\
\hline $17 / 01 / 2012$ & Puerto Lumbreras (Murcia) & Empty tanker overturning & \\
\hline $24 / 01 / 2012$ & Huelva & Tanker overturning & \\
\hline
\end{tabular}

$4 \quad$ Table 2.

\begin{tabular}{|l|c|}
\hline Item & Value \\
\hline Total length & $14.04 \mathrm{~m}$ \\
\hline Inner diameter & $2.34 \mathrm{~m}$ \\
\hline Outer diameter & $2.6 \mathrm{~m}$ \\
\hline Nominal total volume & $56.5 \mathrm{~m}^{3}$ \\
\hline LNG capacity & $21,000 \mathrm{~kg}$ \\
\hline Maximum pressure service & 7 bar \\
\hline Storage Pressure & 1 bar \\
\hline Storage temperature & $-160^{\circ} \mathrm{C}$ \\
\hline Design temperature & $+50^{\circ} \mathrm{C} /-196{ }^{\circ} \mathrm{C}$ \\
\hline Vessel material & Stainless steel $304 \mathrm{LN}$ \\
\hline Vessel thickness & 4 mm (body) $/ 6 \mathrm{~mm}($ bottom $)$ \\
\hline Inner breakwaters & 7 elements $(3 \mathrm{~mm})$ \\
\hline Isolation & Polyurethane $(130 \mathrm{~mm})$ \\
\hline Envelope & Aluminium $(2 \mathrm{~mm})$ \\
\hline Safety valves & 3 (two at 7 bar, one at $9.1 \mathrm{bar})$ \\
\hline
\end{tabular}


Table 3.

\begin{tabular}{|c|c|c|c|c|}
\hline & \multicolumn{2}{|c|}{7 bar } & \multicolumn{2}{|c|}{9.1 bar } \\
\hline & $\begin{array}{l}\text { Explosion } \\
\text { state }\end{array}$ & Final state & $\begin{array}{c}\text { Explosion } \\
\text { state }\end{array}$ & Final state \\
\hline Pressure (kPa) & 700 & 100 & 910 & 100 \\
\hline Temperature (K) & 141 & 112 & 147 & 112 \\
\hline Total mass $(\mathrm{kg})$ & 12000 & 12000 & 12000 & 12000 \\
\hline Mass of liquid (kg) & 11784 & 8996 & 11730 & 8505 \\
\hline Mass of vapor $(\mathrm{kg})$ & 216 & 3004 & 270 & 3495 \\
\hline Vapor specific volume $\left(\mathrm{m}^{3} \cdot \mathrm{kg}^{-1}\right)$ & 0.1096 & 0.502 & 0.085 & 0.502 \\
\hline Liquid specific volume $\left(\mathrm{m}^{3} \cdot \mathrm{kg}^{-1}\right)$ & 0.0028 & 0.0024 & 0.003 & 0.0024 \\
\hline Vapor volume $\left(\mathrm{m}^{3}\right)$ & 23.6 & 1509 & 22.9 & 1755 \\
\hline Liquid volume $\left(\mathrm{m}^{3}\right)$ & 32.9 & 21 & 33.6 & 20 \\
\hline Total volume $\left(\mathrm{m}^{3}\right)$ & 56.5 & 1530 & 56.5 & 1775 \\
\hline Mass vapor fraction & 0.018 & 0.3 & 0.023 & 0.3 \\
\hline 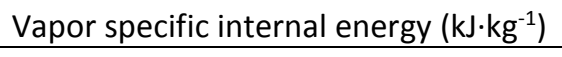 & 763 & 747 & 771 & 747 \\
\hline Liquid specific internal energy $\left(\mathrm{kJ}^{\mathrm{k}} \mathrm{kg}^{-1}\right)$ & 398 & 279 & 418 & 279 \\
\hline Vapor internal energy (MJ) & 164 & 2244 & 208 & 2611 \\
\hline Liquid internal energy (MJ) & 4689 & 2514 & 4900 & 2376 \\
\hline Total internal energy (MJ) & 4854 & 4757 & 5108 & 4987 \\
\hline Explosion energy (MJ) & \multicolumn{2}{|c|}{97} & \multicolumn{2}{|c|}{121} \\
\hline
\end{tabular}

3 *The properties of natural gas have been assimilated to methane and obtained from (Green \& Perry, 2007) 4 and (Younglove \& Ely, 1987)

5 
Table 4.

\begin{tabular}{|c|c|c|c|c|}
\hline & \multicolumn{2}{|c|}{7 bar } & \multicolumn{2}{|c|}{9.1 bar } \\
\hline & $\begin{array}{l}\text { Explosion } \\
\text { state }\end{array}$ & Final state & $\begin{array}{l}\text { Explosion } \\
\text { state }\end{array}$ & Final state \\
\hline Pressure (kPa) & 700 & 100 & 910 & 100 \\
\hline Temperature $\left({ }^{\circ} \mathrm{C}\right)$ & 141 & 112 & 147 & 112 \\
\hline Total mass (kg) & 12000 & 12000 & 12000 & 12000 \\
\hline Mass of liquid (kg) & 11784 & $\mathrm{nn}$ & 11730 & $\mathrm{nn}$ \\
\hline Mass of vapor $(\mathrm{kg})$ & 216 & $\mathrm{nn}$ & 270 & $\mathrm{nn}$ \\
\hline Vapor specific volume $\left(\mathrm{m}^{3} \cdot \mathrm{kg}^{-1}\right)$ & 0.1096 & 0.502 & 0.085 & 0.502 \\
\hline Liquid specific volume $\left(\mathrm{m}^{3} \cdot \mathrm{kg}^{-1}\right)$ & 0.0028 & 0.0024 & 0.003 & 0.0024 \\
\hline Vapor specific internal energy $\left(\mathrm{kJ} \cdot \mathrm{kg}^{-1}\right)$ & 763 & 691 & 771 & 681 \\
\hline Liquid specific internal energy $\left(\mathrm{kJ}^{\mathrm{k}} \mathrm{kg}^{-1}\right)$ & 398 & 364 & 418 & 378 \\
\hline Vapor specific entropy $\left(\mathrm{kJ} \cdot \mathrm{kg}^{-1} \cdot \mathrm{K}^{-1}\right)$ & 8.96 & 9.51 & 8.87 & 9.51 \\
\hline Liquid specific entropy $\left(\mathrm{kJ} \cdot \mathrm{kg}^{-1} \cdot \mathrm{K}^{-1}\right)$ & 5.78 & 4.95 & 5.91 & 4.95 \\
\hline Vapor enthalpy $\left(\mathrm{kJ} \cdot \mathrm{kg}^{-1}\right)$ & $\mathrm{nn}$ & 797 & $\mathrm{nn}$ & 797 \\
\hline Liquid enthalpy $\left(\mathrm{kJ} \cdot \mathrm{kg}^{-1}\right)$ & $\mathrm{nn}$ & 280 & $\mathrm{nn}$ & 280 \\
\hline Vapor ratio of saturated vapor, $X_{V}$ & & 0.88 & & 0.86 \\
\hline Vapor ratio of saturated liquid, $X_{L}$ & & 0.18 & & 0.21 \\
\hline Explosion energy of the vapor (MJ) & \multicolumn{2}{|c|}{16} & \multicolumn{2}{|c|}{24} \\
\hline Explosion energy of the liquid (MJ) & \multicolumn{2}{|c|}{406} & \multicolumn{2}{|c|}{472} \\
\hline Total explosion energy (MJ) & \multicolumn{2}{|c|}{422} & \multicolumn{2}{|c|}{496} \\
\hline
\end{tabular}

*The properties of natural gas have been assimilated to methane and obtained from (Green \& Perry, 2007) and (Younglove \& Ely, 1987)

nn means that these values are not needed for the calculations

Table 5.

\begin{tabular}{|c|c|c|c|c|c|c|c|c|c|}
\hline \multirow{2}{*}{$\begin{array}{c}\text { Pressure } \\
\text { (bar) }\end{array}$} & \multicolumn{3}{|c|}{ Planas-Cuchi et al } & \multicolumn{3}{c|}{ TNO original } & \multicolumn{3}{c|}{ TNO with $\boldsymbol{\beta}=\mathbf{0 . 5}$} \\
\cline { 2 - 11 } & $\begin{array}{c}W_{T N T} \\
(\mathrm{~kg})\end{array}$ & $\begin{array}{c}d_{n} \\
\left(\mathrm{~m} \cdot \mathrm{kg}^{-1 / 3}\right)\end{array}$ & $\begin{array}{c}\Delta P \\
(\mathrm{bar})\end{array}$ & $\begin{array}{c}E_{\text {pwave }} \\
(\mathrm{MJ})\end{array}$ & $\begin{array}{c}\bar{R} \\
(--)\end{array}$ & $\begin{array}{c}\Delta P \\
(\mathrm{bar})\end{array}$ & $\begin{array}{c}E_{\text {pwave }} \\
\text { (MJ) }\end{array}$ & $\begin{array}{c}\bar{R} \\
(--)\end{array}$ & $\begin{array}{c}\Delta P \\
\text { (bar) }\end{array}$ \\
\hline 7 & 41 & 45.6 & $\mathbf{0 . 0 2 1}$ & 1686 & 4.89 & $\mathbf{0 . 0 5 5}$ & 843 & 6.17 & $\mathbf{0 . 0 4 5}$ \\
\hline 9.1 & 52 & 42.3 & $\mathbf{0 . 0 2 3}$ & 1984 & 4.64 & $\mathbf{0 . 0 5 9}$ & 992 & 5.84 & $\mathbf{0 . 0 4 9}$ \\
\hline
\end{tabular}

8

9 


\section{FIGURES}

$2 \quad$ Figure 1.

3

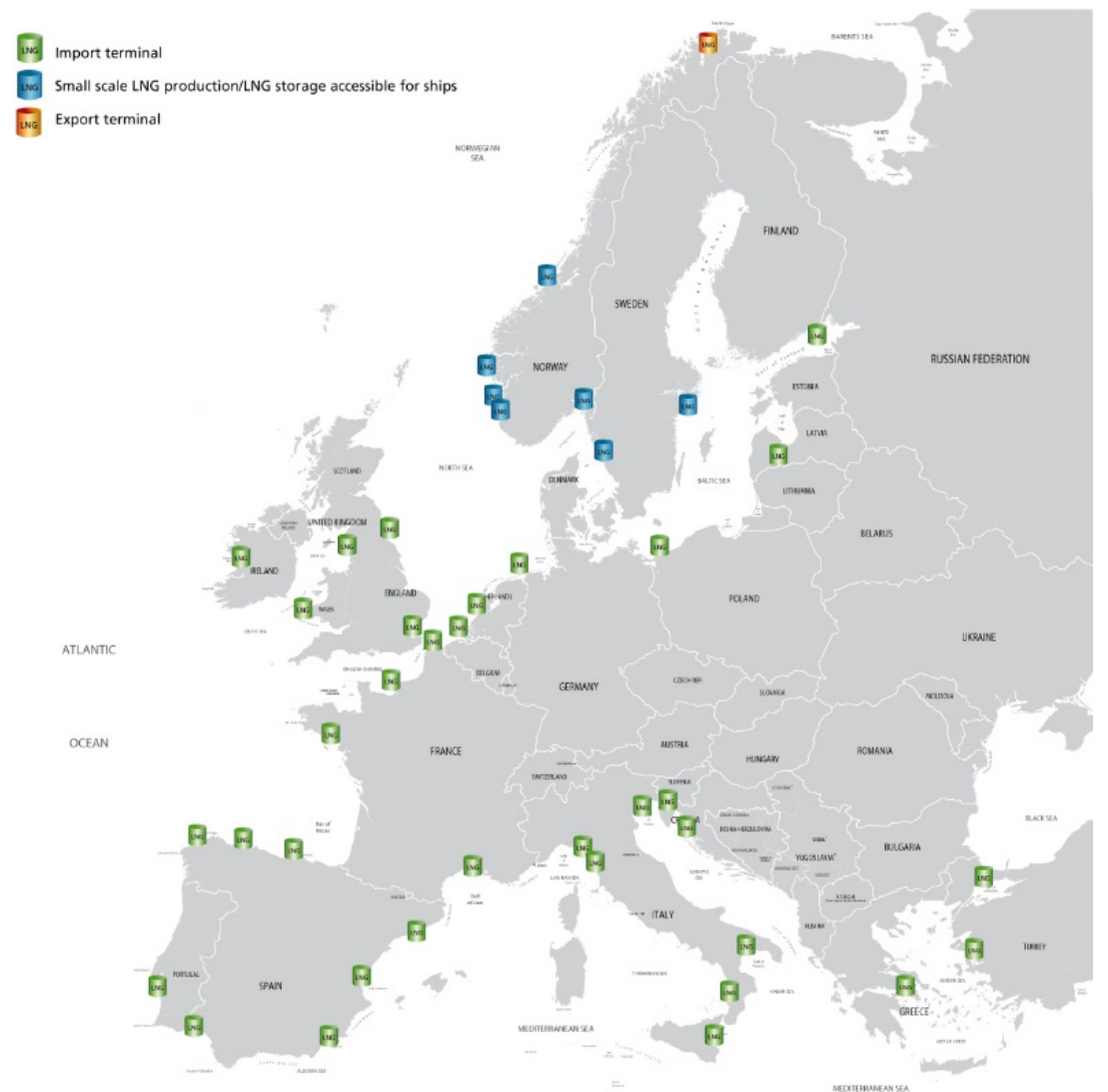

4

5 
2 Figure 2.

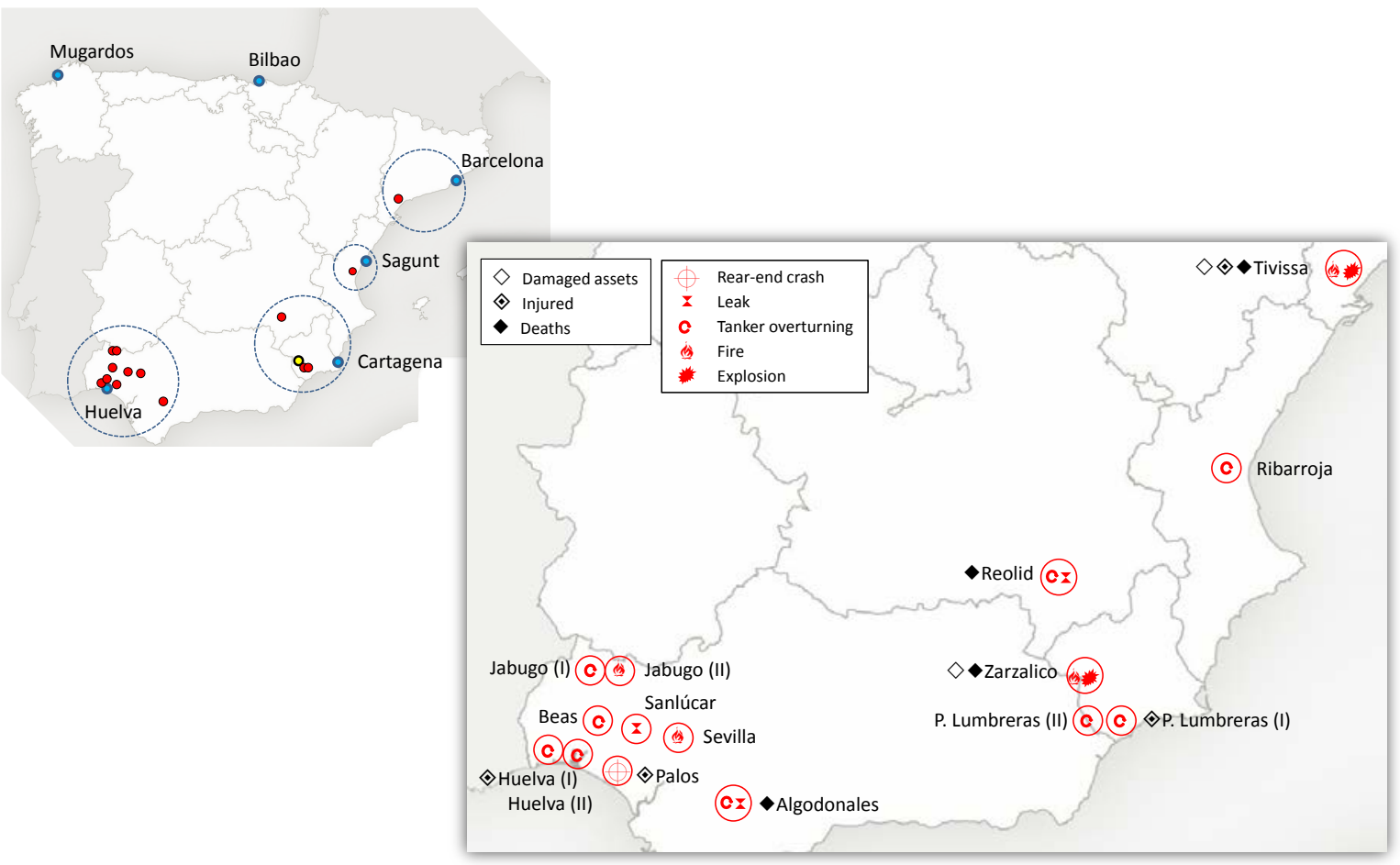


$2 \quad$ Figure 3.

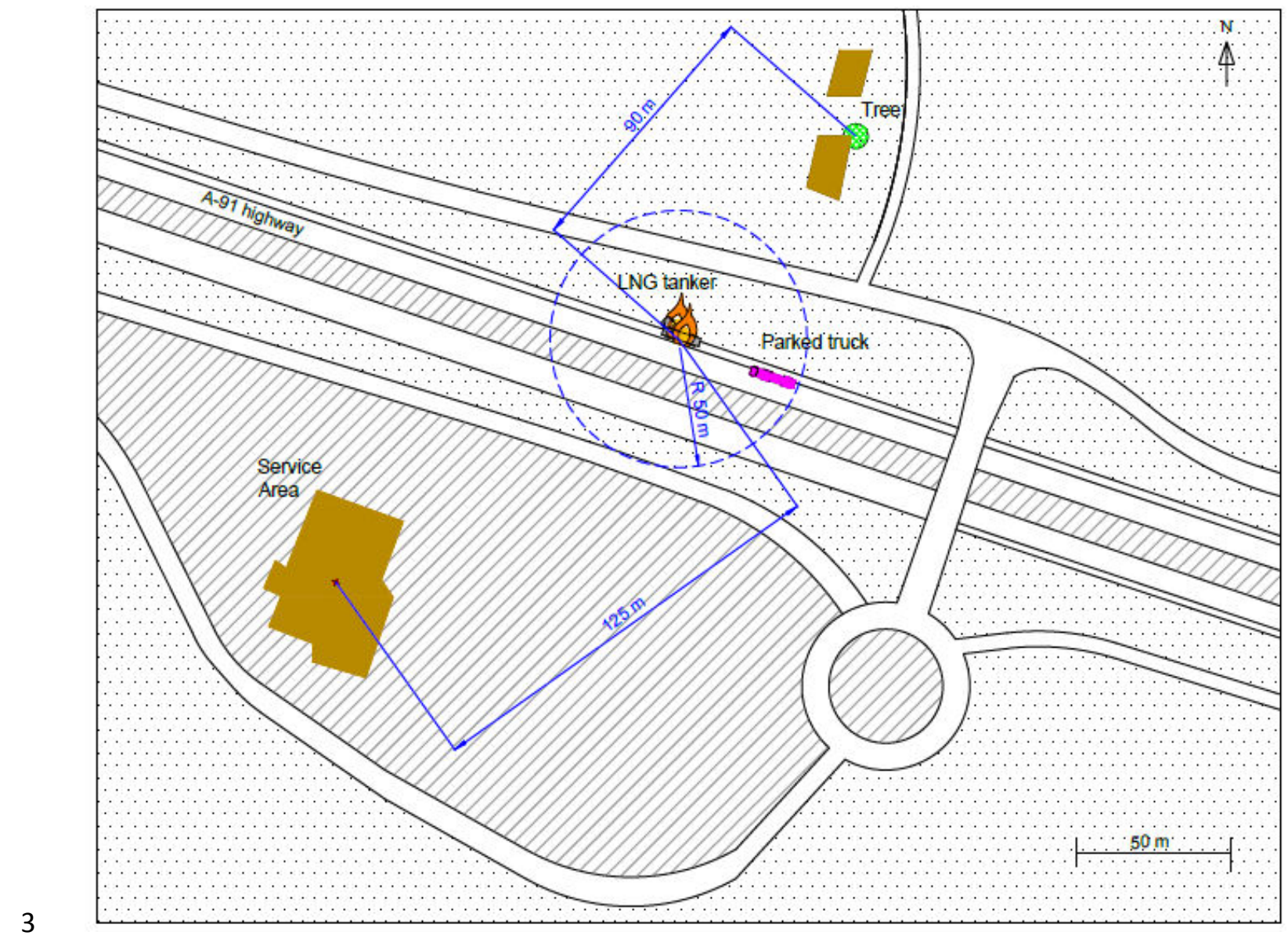

4 
$2 \quad$ Figure 4.

3

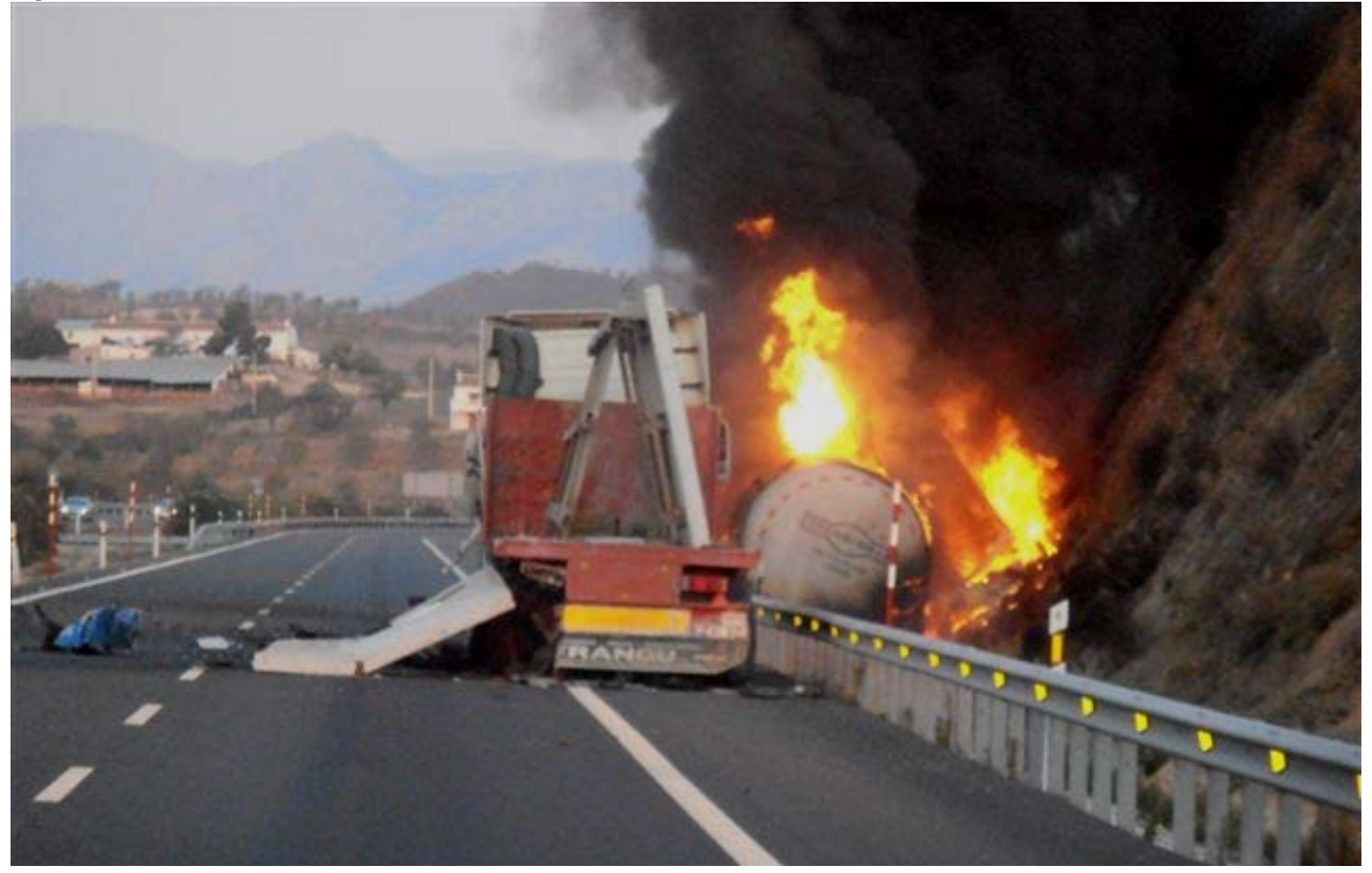

4 
$2 \quad$ Figure 5.

3

4

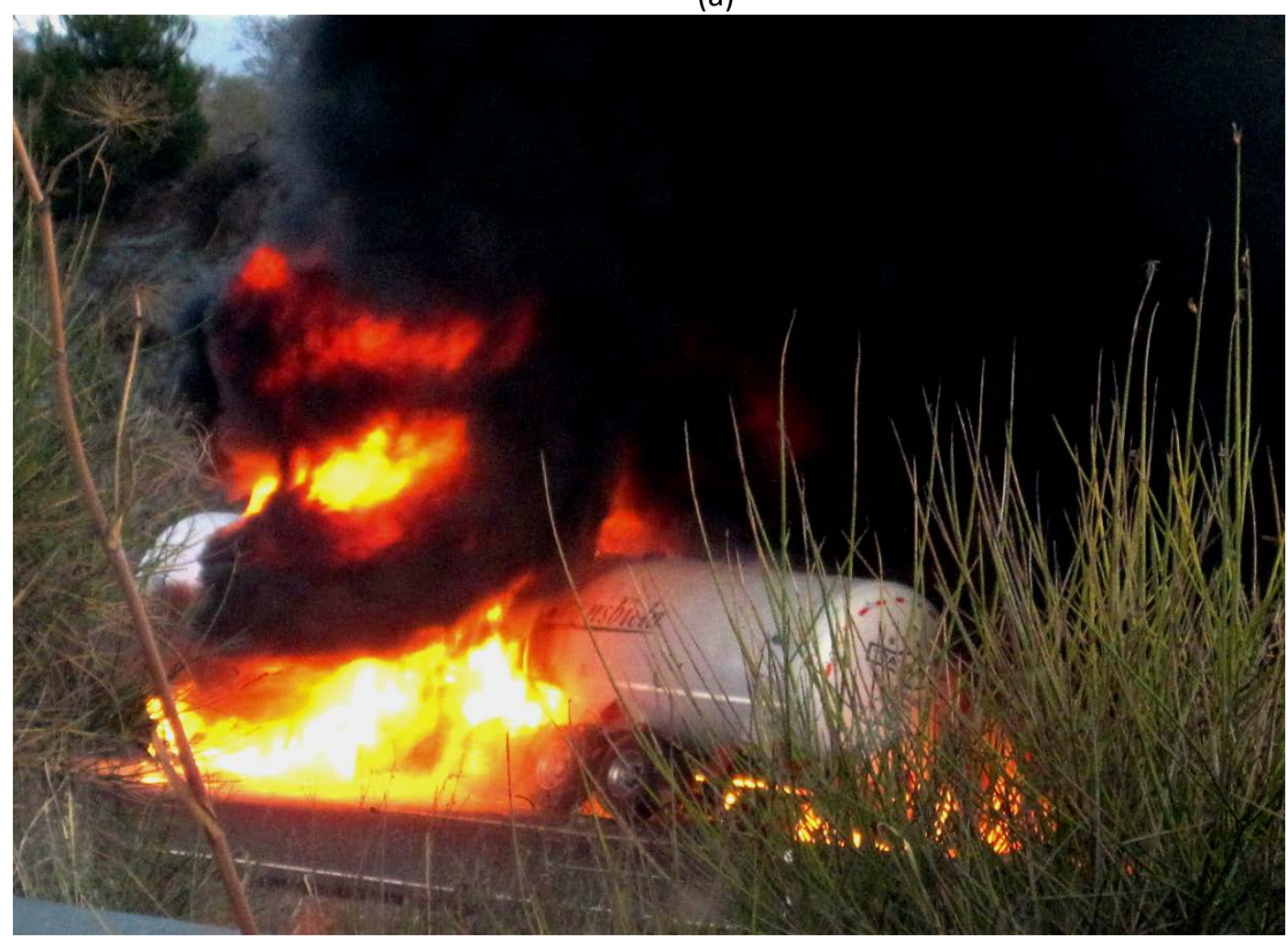

5

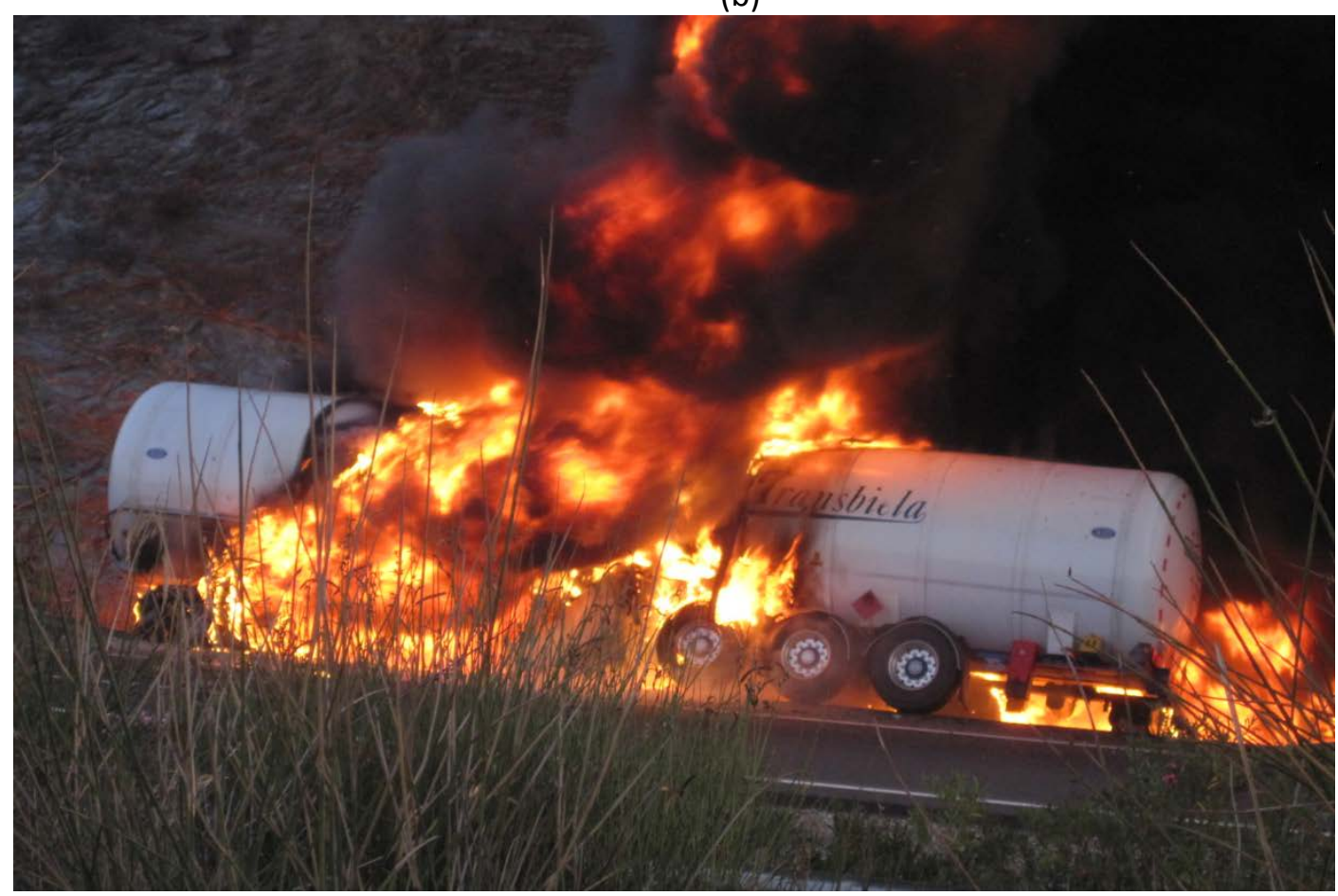


Figure 6.

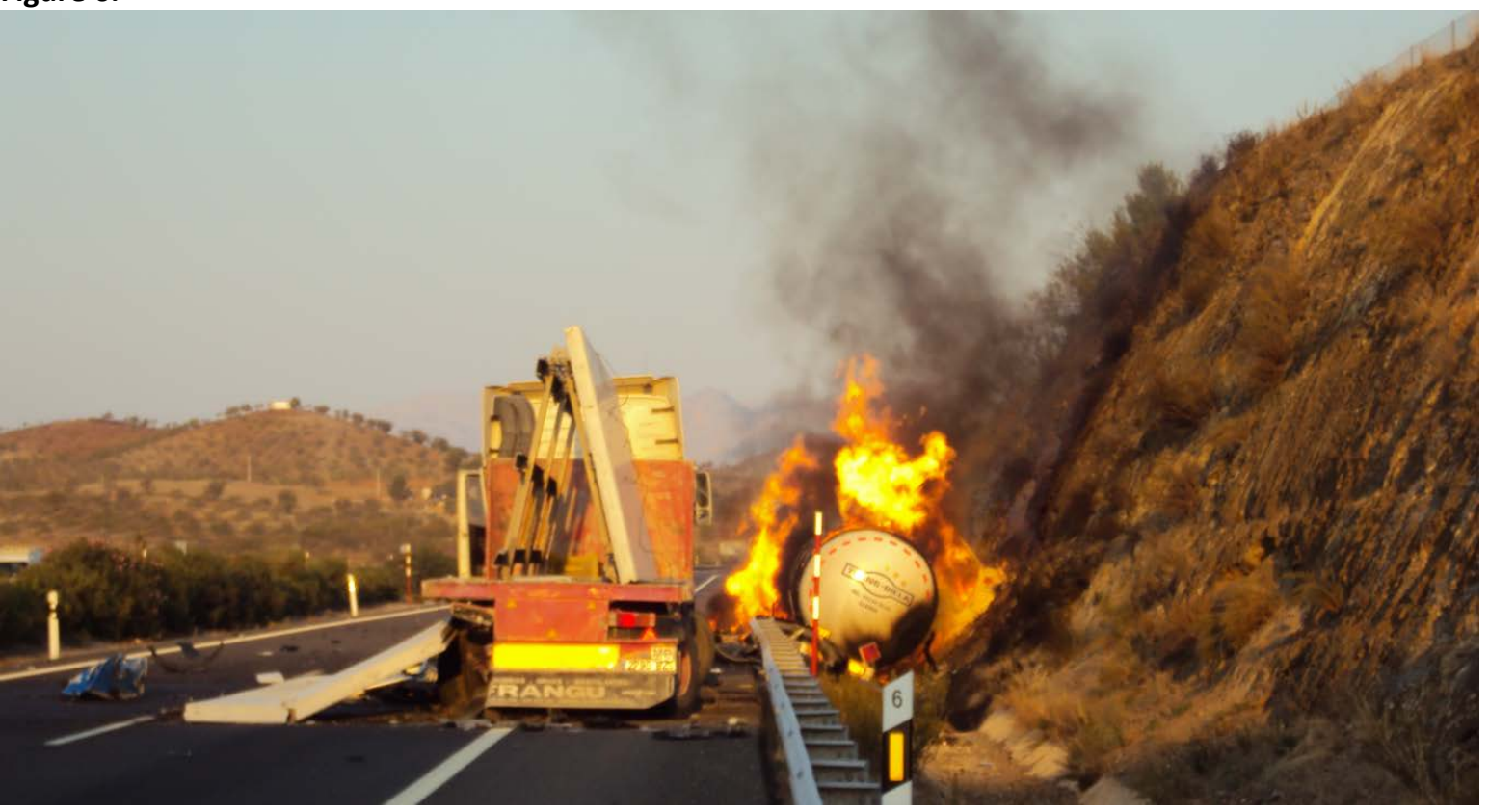

3

Figure 7.

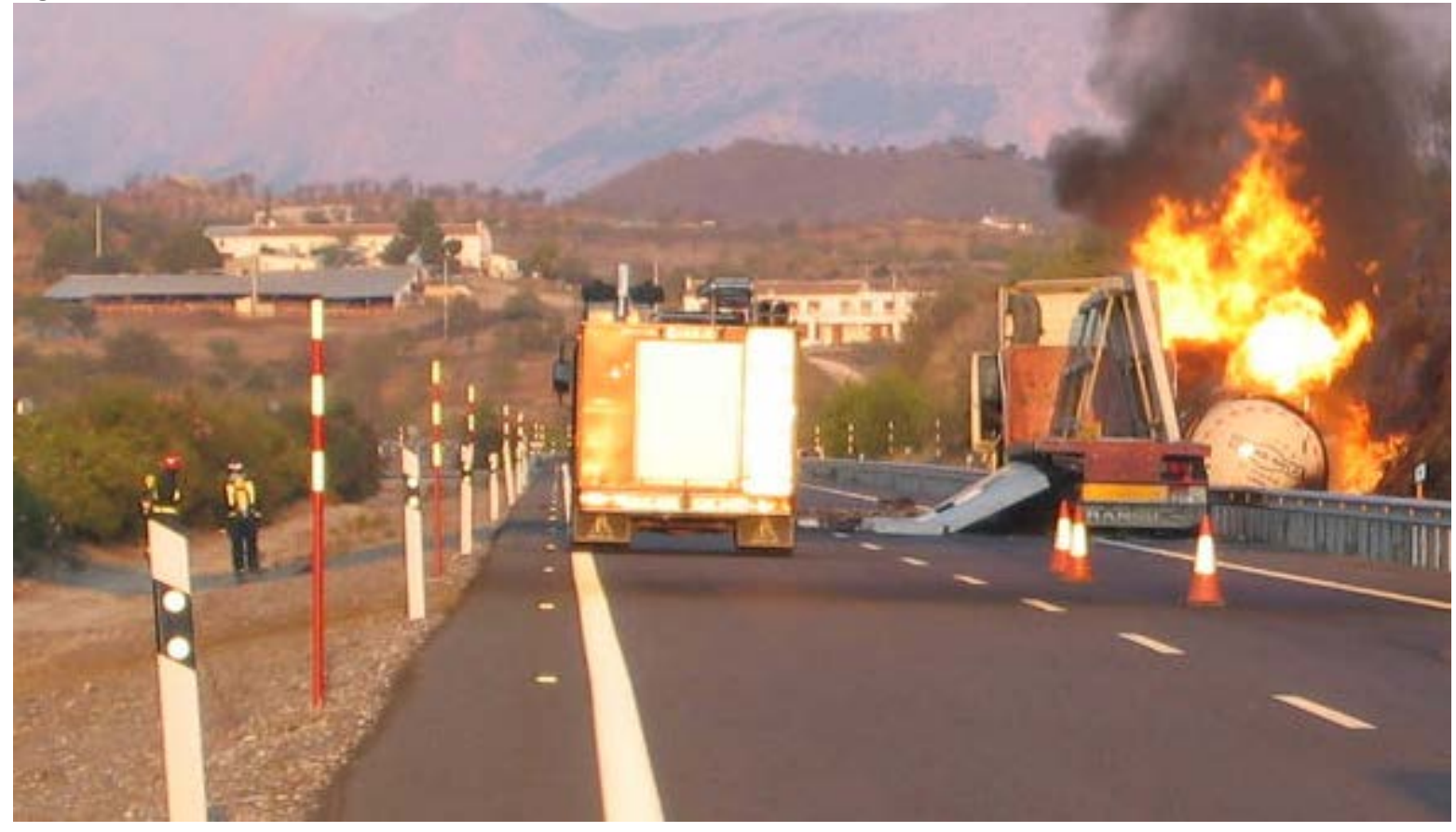

6 
$1 \quad$ Figure 8.

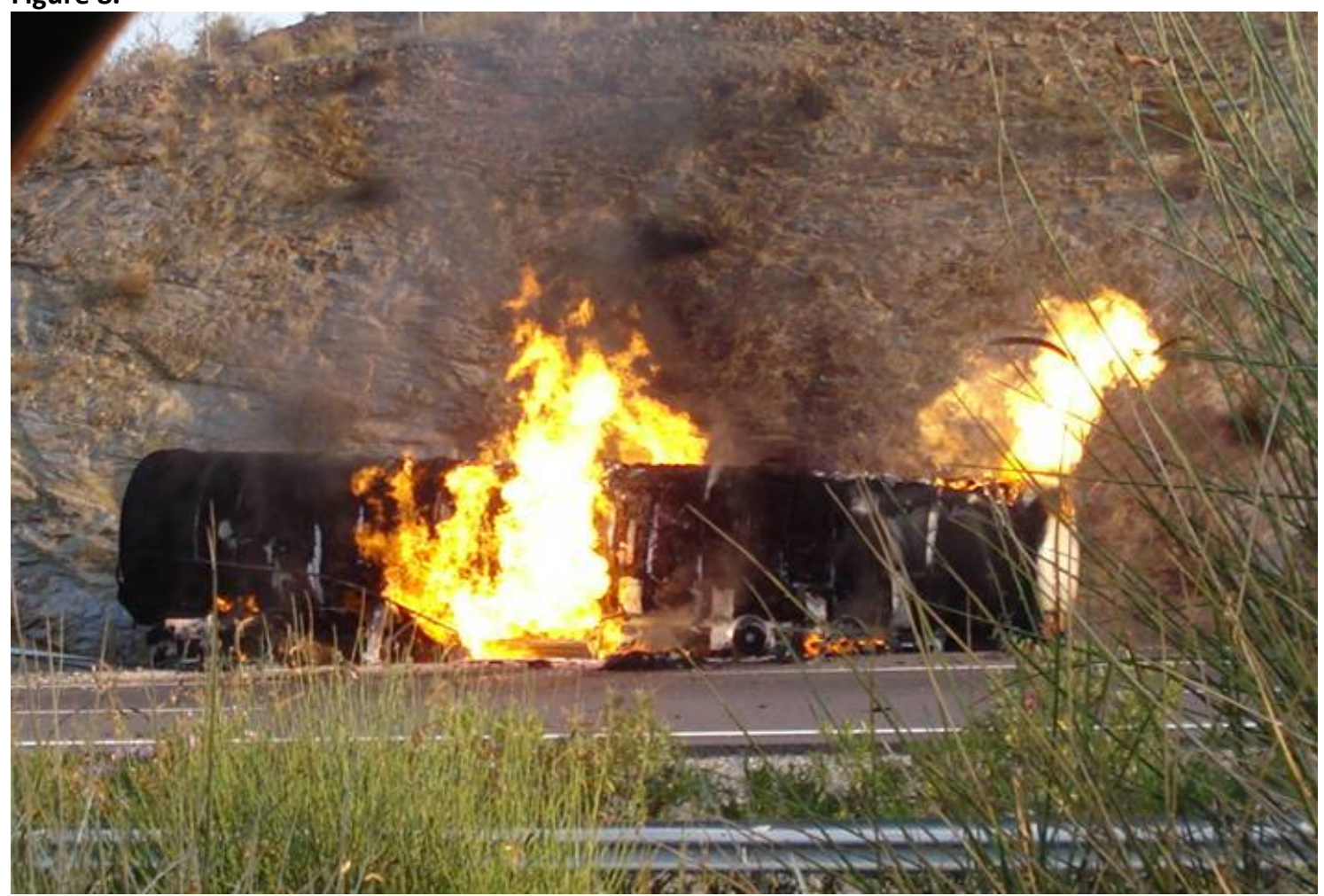

\section{$3 \quad$ Figure 9}
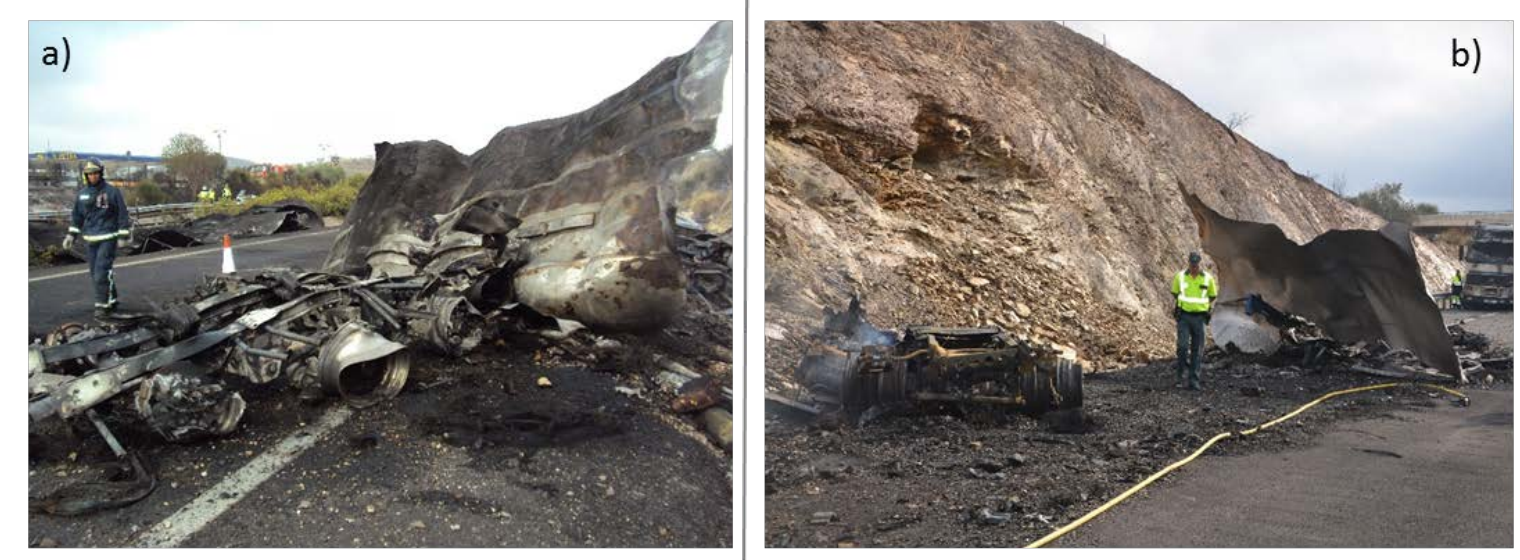

c)

d)
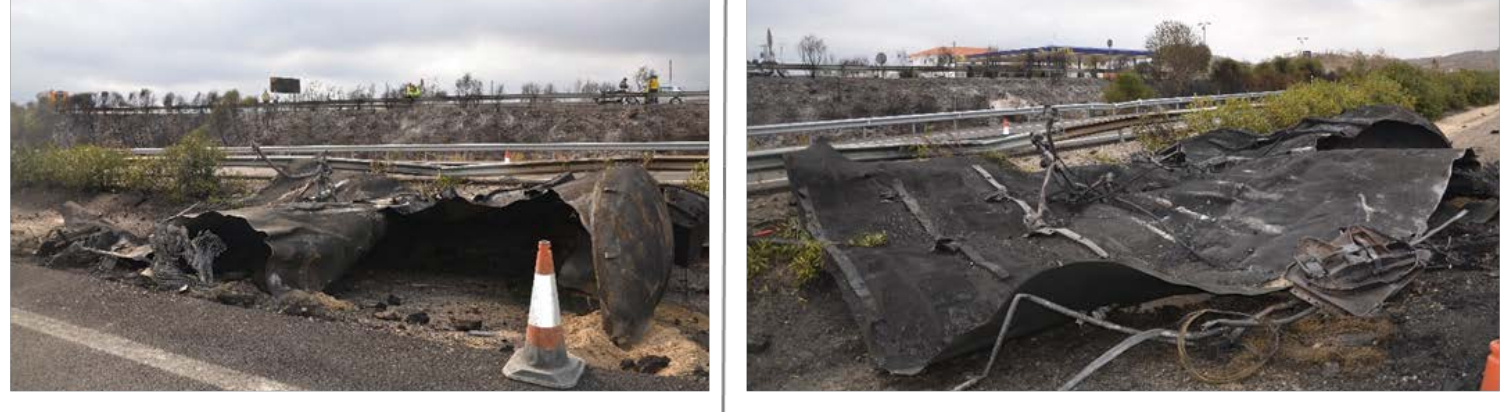
1

2 Figure 10.

3

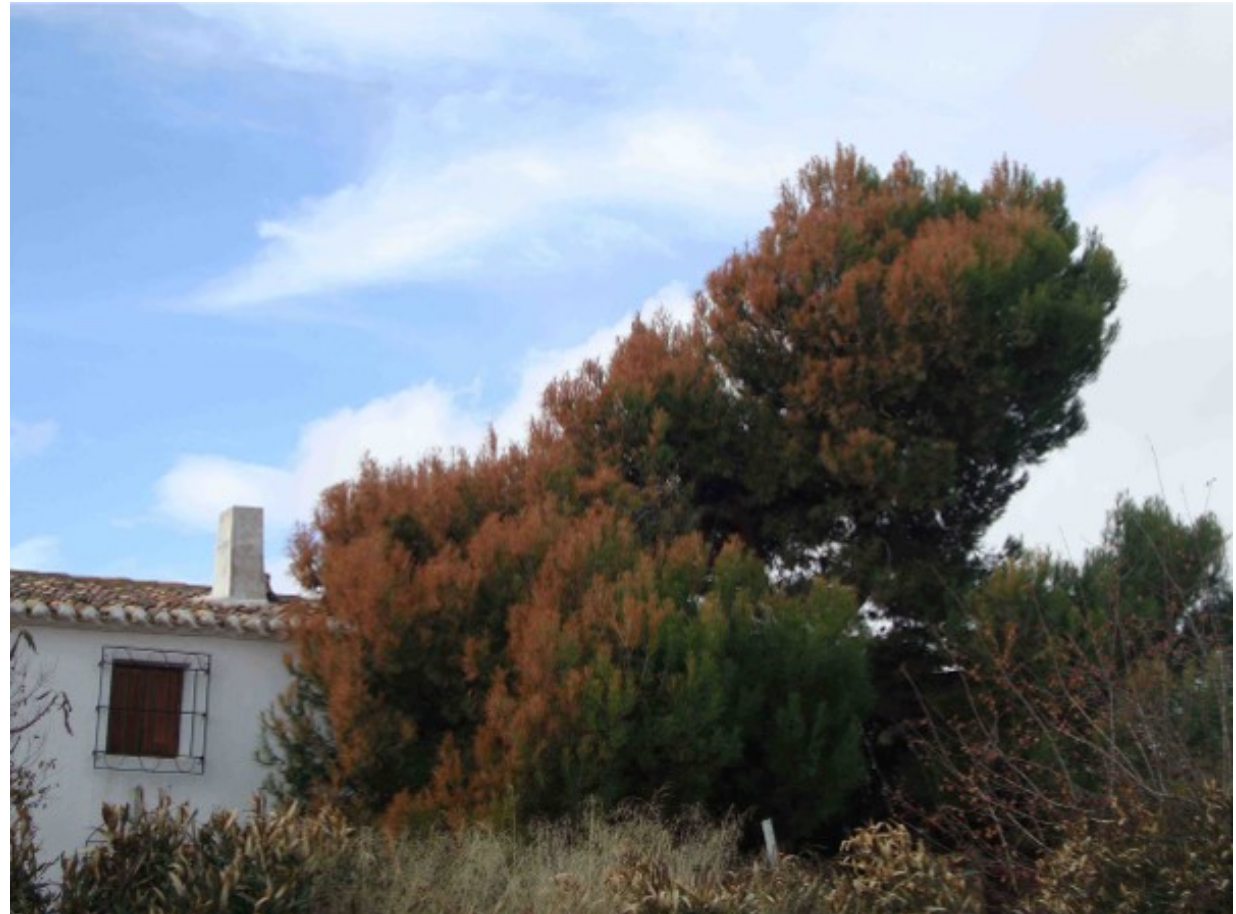

4

$5 \quad$ Figure 11.

6

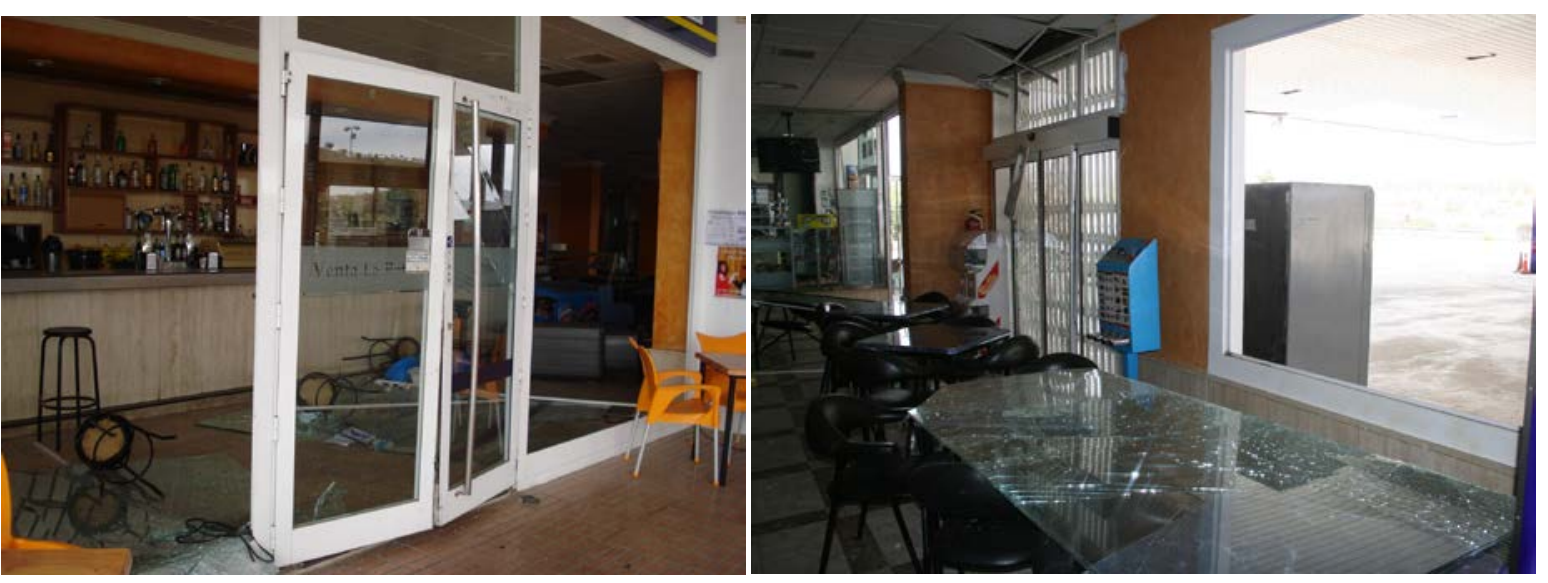

8

9

10 
2 Figure 12.

3

Figure 12.

4

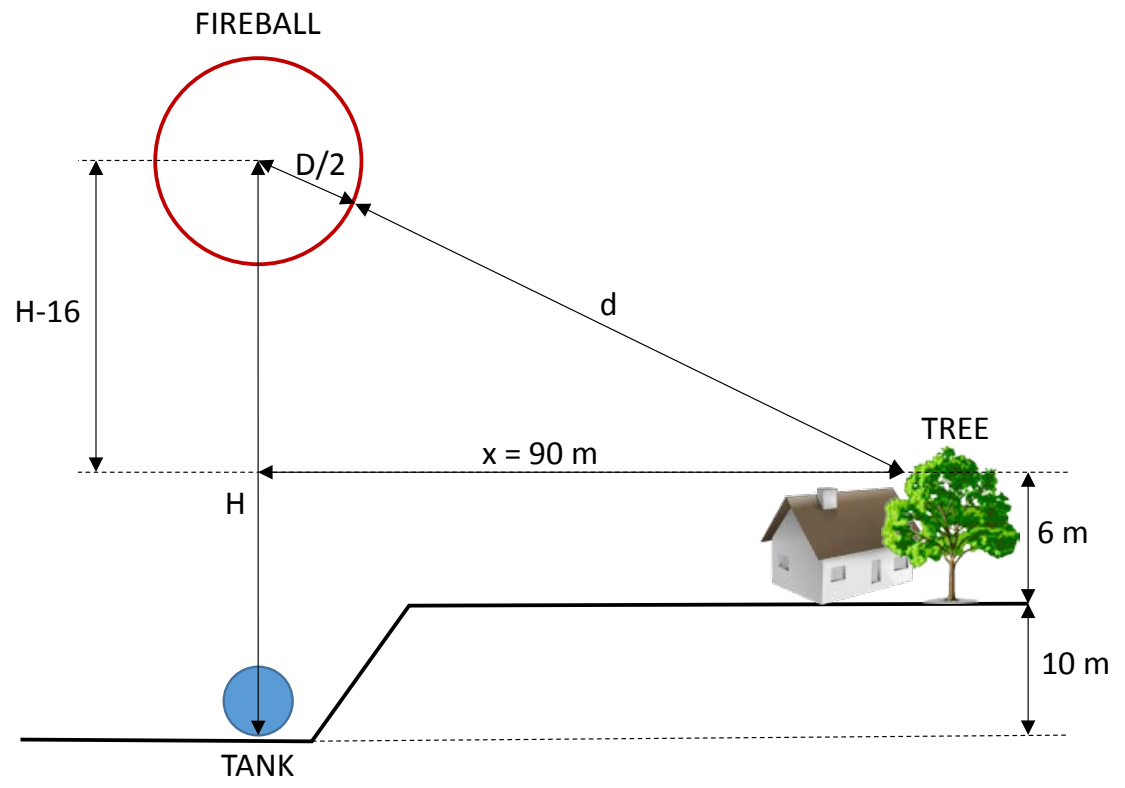

5

6

$7 \quad$ Figure 13.

8

9

Hemispherical propagation of the pressure wave over the ground

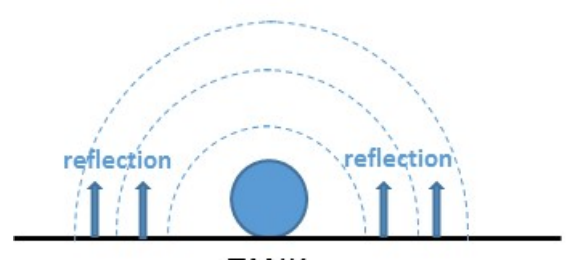

TANK
Propagation of the pressure wave over the ground on the presence of a talus

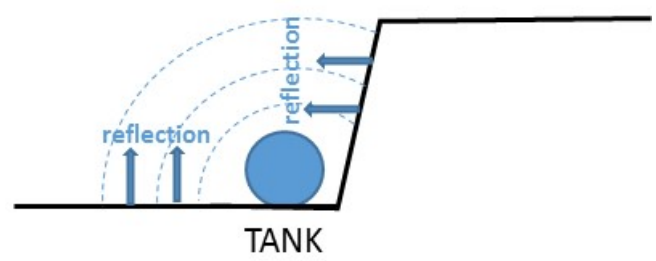

10 